\title{
Comparison of seismic performance of steel frames equipped with diagonal and chevron viscous damper under near and far field earthquakes
}

\author{
Davood Sedaghat Shaygan ${ }^{1}$, Rasoul Nodeh Farahoni ${ }^{2}$, Alireza Lork ${ }^{3}$, \\ Gholamreza Abdollahzadeh ${ }^{4}$ \\ ${ }^{1}$ Department of Civil Engineering, Qazvin Branch, Islamic Azad University, Qazvin, Iran \\ ${ }^{2,4}$ Department of Civil Engineering, Babol Noshirvani University of Technology, Babol, Iran \\ ${ }^{3}$ Department of Civil Engineering, Safadasht Branch, Islamic Azad University, Tehran, Iran \\ ${ }^{1}$ Corresponding author \\ E-mail:1'dshayegan@hotmail.com, ${ }^{2}$ nemesis00700@gmail.com, ${ }^{3}$ lorkdr@gmail.com, \\ 4abdollahzadeh@nit.ac.ir
}

Received 2 April 2018; accepted 12 April 2018

DOI https://doi.org/10.21595/vp.2018.19860

Check for updates

\begin{abstract}
A complete comparison of seismic behavior of the application of Diagonal and Chevron Viscous Damper in steel structures is presented in this paper. OpenSees software is used for the numerical modeling of structures. Fifteen numbers of earthquake records are applied to the structures and full nonlinear time history analysis is done. Force-displacement of chevron braces with and without a damper are compared and the results of IDA curves are also presented for different percentiles.
\end{abstract}

Keywords: steel bracing frame, viscous fluid damper, energy dissipation, nonlinear dynamic analysis.

\section{Introduction}

There are two common types of steel chevron and diagonal bracing frames, equipped with viscose fluid damper are studied in this paper. All dimensional specifications, as well as the specifications of the cross-sections and materials used for the beams, columns, and braces of the frame models, are considered as similar. OpenSees software is used to model the structures and a suit of fifteen earthquake records are used for nonlinear time history analysis. Viscous dampers have a great displacement under strong ground motions and absorb earthquake energy and less damage will occur in structural components. It has been established that the base shear and displacements are decreased by using viscous dampers in steel structures. The main advantages of viscous dampers are on the hysteretic behavior in the main structural members. One of the most practical and effective methods for controlling the behavior of the structures is using viscous dampers. The designed procedures of dampers are based on the structural period, soil type and structural components. [1].

\section{Structural modeling}

In this research, there are four story steel frame structures with chevron and diagonal braces are studied and designed in ETABS software [1]. The height of each floor is 3 meters and the length of each bay is 5 meters. Viscous dampers in the OpenSees software have been placed at the junction of the beam and the column [2-5]. In Table 2, the details information of earthquake records is presented in Table 2. The record selection has been done from FEMA-P695. Incremental dynamic analysis (IDA) is used in this study to obtain the nonlinear behaviour of structures.

Table 1. Sections assigned in each of steel frames

4-story structure with diagonal and chevron braces

\begin{tabular}{|c|c|c|} 
Column sections & Beam sections & Brace sections \\
\hline IPB 180 & IPE270 & TUBO $80 * 80 * 8$ \\
\hline
\end{tabular}


Table 2. Specifications of far field and near field accelerograms [2]

\begin{tabular}{|c|c|c|c|c|c|c|c|}
\hline \multicolumn{7}{|c|}{ Specifications of the Selected Records } \\
\hline $\begin{array}{c}\text { Record } \\
\text { No. }\end{array}$ & Earthquake name & Station name & Year & Magnitude & Soil type & Fault type & PGA \\
\hline 1 & Northridge & Beverly Hills-Mulhol-USC & 1994 & 6.7 & D & Thrust & 0.52 \\
\hline 2 & Northridge & Canyon Country-WLC-USC & 1994 & 6.7 & D & Thrust & 0.48 \\
\hline 3 & Duzce, Turkey & Bolu-ERD & 1999 & 7.1 & D & Strike-slip & 0.82 \\
\hline 4 & Hector Mine & Hector-SCSN & 1999 & 7.1 & C & Strike-slip & 0.34 \\
\hline 5 & Imperial Valley & Delta-ENAMUCSD & 1979 & 6.5 & D & Strike-slip & 0.35 \\
\hline 6 & Imperial Valley & El Centro Array \#11-USGS & 1979 & 6.5 & D & Strike-slip & 0.38 \\
\hline 7 & Kobe, Japan & Nishi-Akashi-CUE & 1995 & 6.9 & C & Strike-slip & 0.51 \\
\hline 8 & Kobe, Japan & Shin-Osaka-CUE & 1995 & 6.9 & D & Strike-slip & 0.24 \\
\hline 9 & Kocaeli, Turkey & Duzce-ERD & 1999 & 7.5 & D & Strike-slip & 0.36 \\
\hline 10 & Kocaeli, Turkey & Arcelik-KOERI & 1999 & 7.5 & C & Strike-slip & 0.22 \\
\hline 11 & Landers & Yermo Fire Station-CDMG & 1992 & 7.3 & D & Strike-slip & 0.24 \\
\hline 12 & Landers & Coolwater-SCE & 1992 & 7.3 & D & Strike-slip & 0.42 \\
\hline 13 & Loma Prieta & Capitola-CDMG & 1989 & 6.9 & D & Strike-slip & 0.53 \\
\hline 14 & Loma Prieta & Gilroy Array \#3-CDMG & 1989 & 6.9 & D & Strike-slip & 0.56 \\
\hline 15 & Manjil, Iran & Abbar-BHRC & 1990 & 7.4 & C & Strike-slip & 0.51 \\
\hline
\end{tabular}

\section{Incremental Dynamic Analysis (IDA)}

A full nonlinear time history analysis has been done based on the IDA procedure. The results of nonlinear time history have been shown in Figures 1 and 2. These figures shows the behavior of structures from linear to nonlinear levels. Maximum inter story drift is considered as an Engineering Demand Parameter (EDP) in diagonal and chevron bracing with a viscous damper and $\mathrm{Sa}\left(\mathrm{T}_{1}, 5 \%\right)$ as an Intensity Measures (IM). The results are for the frame with chevron bracing with a viscous damper and with diagonal bracing with a viscous damper. To better understanding of the performance of the structures, the nonlinear behavior of structural components is studied. Figures 3 is shown the hysteretic behavior of chevron braces with and without viscous dampers. Figure 4 is shown the hysteretic behavior of diagonal braces with and without viscous damper. The tight loops are the better performance of viscous structures.

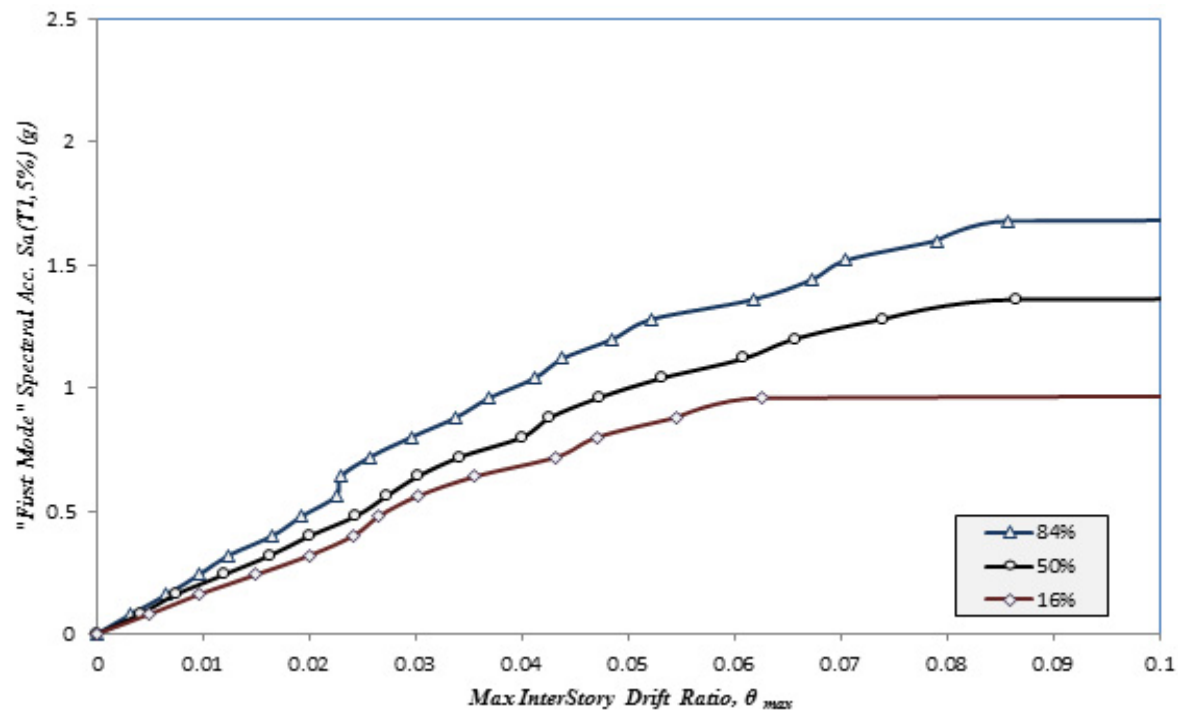

Fig. 1. Summary of IDA curves obtained for a 4-story structural frame with chevron bracing with a viscous damper 


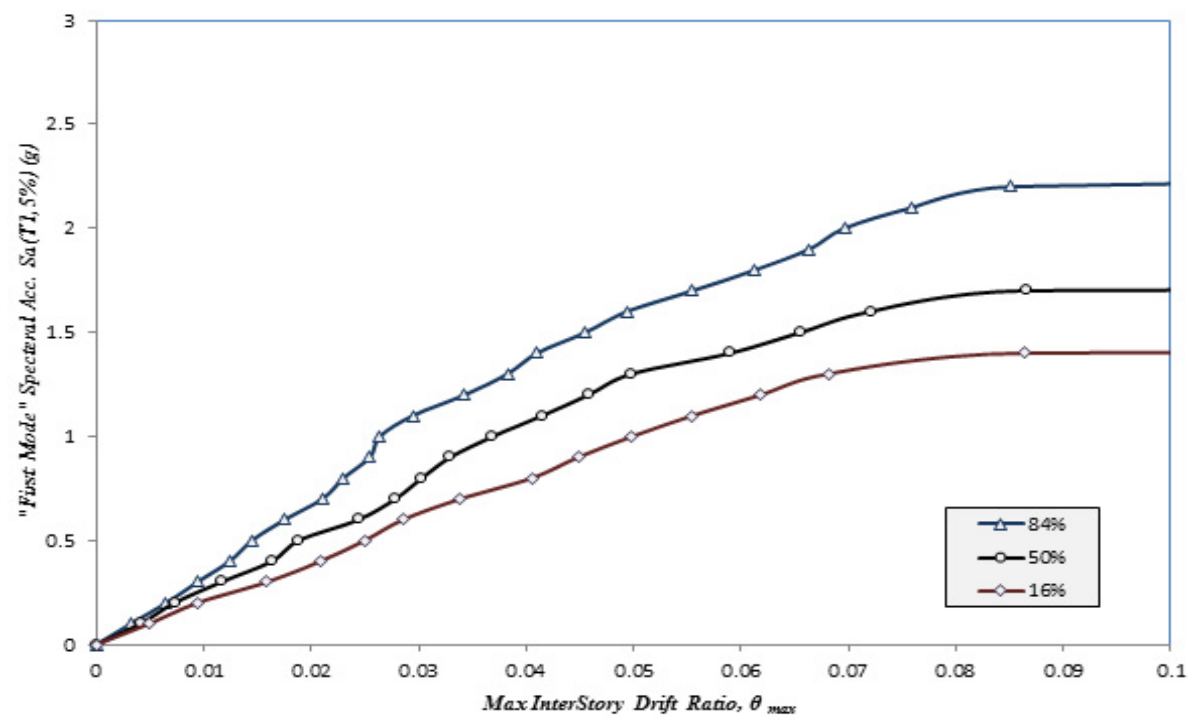

Fig. 2. Summary of IDA curves obtained for a 4-story structural frame with diagonal bracing with a viscous damper

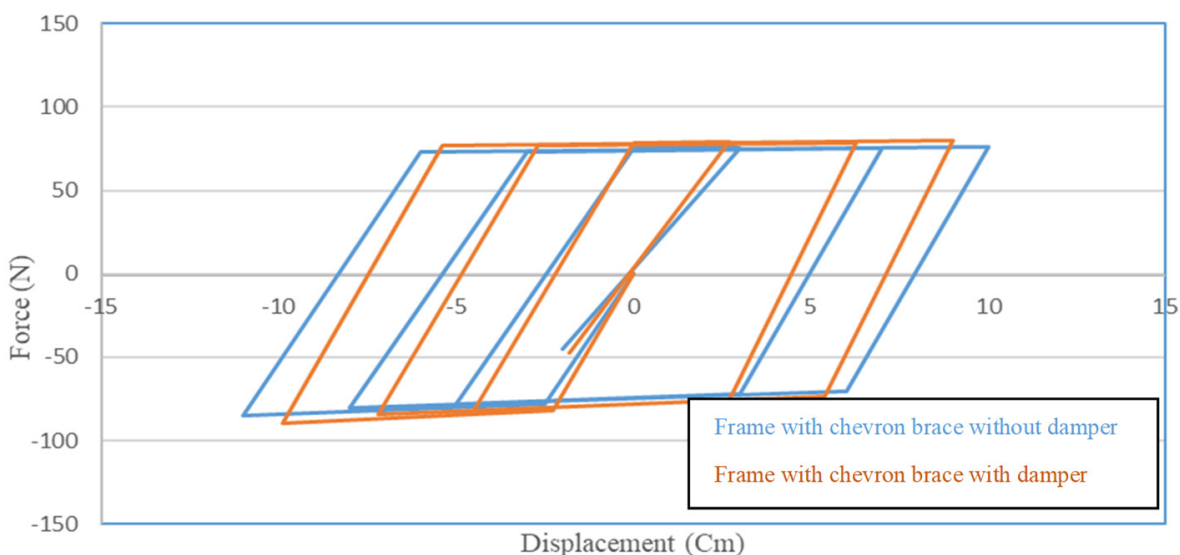

Fig. 3. Comparison of the curves of the frame with chevron braces with and without damper

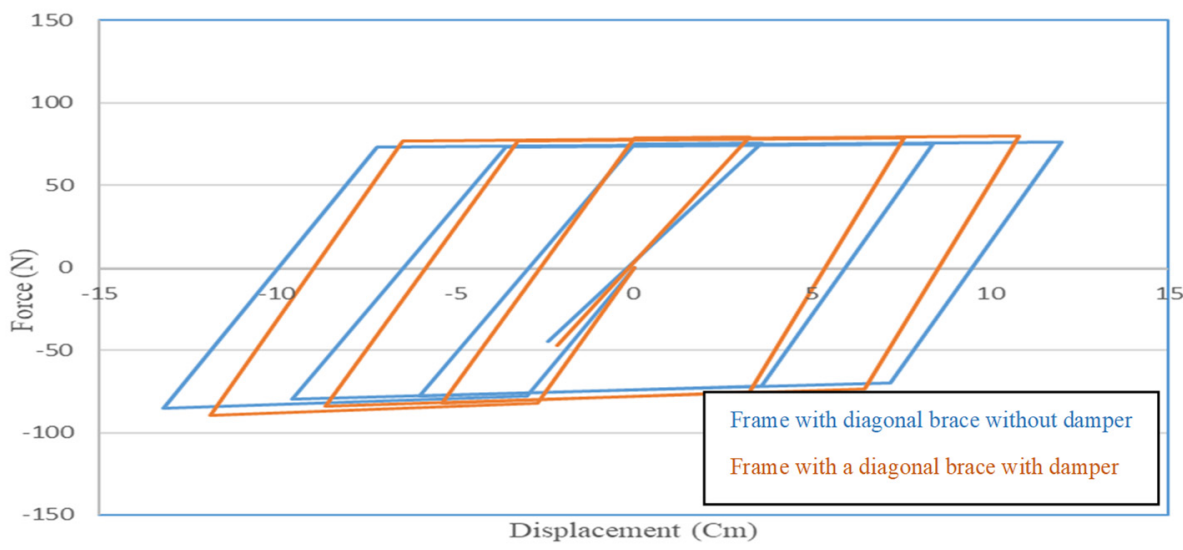

Fig. 4. Comparison of the curves of the frame with diagonal braces with and without damper 


\section{Conclusions}

In this paper, nonlinear behavior of steel frames with chevron and diagonal braces were considered. The effects of viscous dampers were considered in steel frames. The results show that the viscous dampers have a great effects on the hysteretic behavior of the steel frames and has less displacements. Chevron braces has better performance compared to the diagonal braces. The results indicate that the viscous dampers are improved the seismic performance of the structures.

\section{References}

[1] ATC-58, Guidelines for Seismic Performance Assessment of Buildings. Applied Technology Council. Washington, D.C., 2011.

[2] Quantification of Building Seismic Performance Factor. Report No. FEMA-P695. Federal Emergency Management Agency, Washington, D.C., 2009.

[3] Baker J. W. Efficient Analytical Fragility Function Fitting Using Dynamic Structural Analysis. Stanford University, 2014.

[4] Fanaien, Ezzatshoar S. Studying the seismic behavior of gate braced frames by incremental dynamic analysis (IDA). Journal of Constructional Steel Research, Vol. 99, 2014, p. 111-120, https://doi.org/10.1016/j.jcsr.2014.04.08

[5] Soltangharaei V., Razi M., Gerami M. Comparative evaluation of behavior factor of SMRF structures for near and far fault ground motions. Periodica Polytechnica Civil Engineering, Vol. 60, Issue 1, 2016, p. 75-82, https://doi.org/10.3311/PPci.7625 